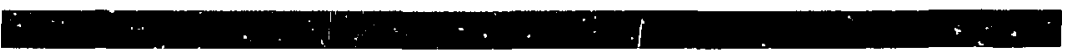

\title{
SOKE OPTIMIZATIONS OF THE ANIMAL CODE
}

\author{
W. T. Fletcher
}

October 9, 1975

Prepared tor U.S. Energy Research \& Devetopment

Administration under contract No. W-7405-Ëng-48

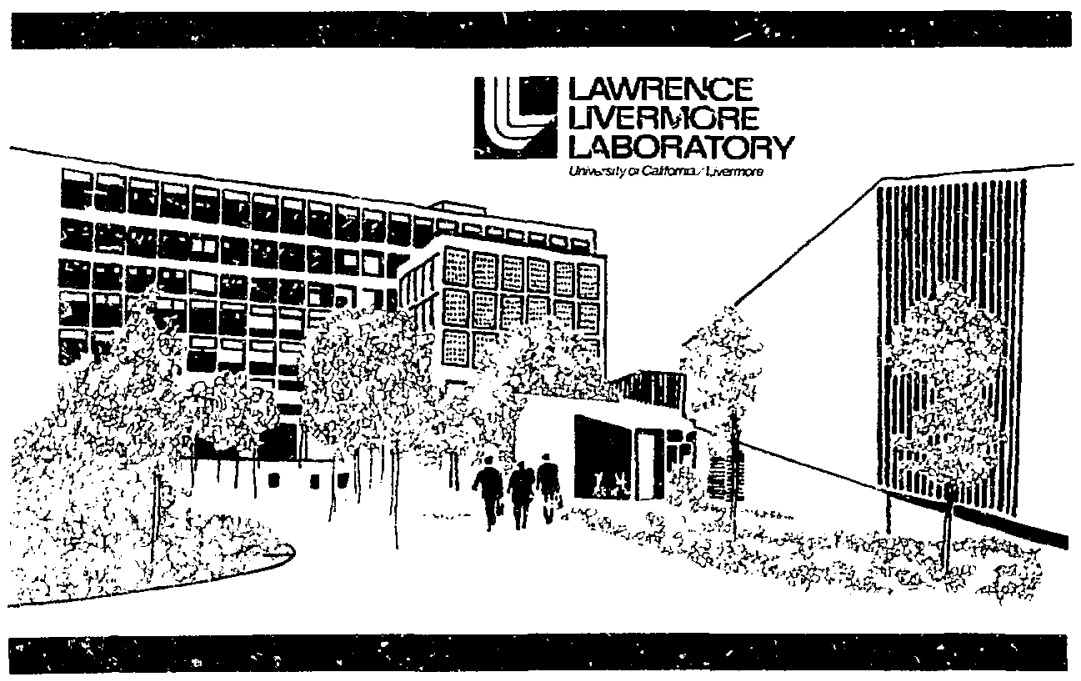




\section{NOTICE}

"This report was prepared as an account of work sponsored by the United States Gwernment. Neither the United States nor the United States Eneray Reseatch Development Administration, nor any of their emplayees, nor any of their contractors, subcontractors, or their employees, tiokes any 1. inty, express or implied, or assumes any leasl liablitity or responsibility for ihe cocuracy, completeness or usefulness of any information, apparatus, product or process disclosed, or represents that its use would not infrisge privately.awned rights."

Printed in the United States of America Availabie from

National Technical Information Service U.S. Department of Commerce 5285 Port Royal Road Springfield, Virginia 22151

Price: Printed Copy $\$ \_$; Microfiche $\$ 2.25$

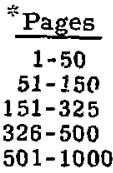

NTIS Selling Price

$\$ 4.00$

$\$ 5.45$

$\$ 7.60$

$\$ 10.60$

$\$ 13.60$ 


\title{
近 \\ LAWRENCE LNERNORE LABORATORY \\ university o/ Caftomia, Livermore, Cattomia 94550
}

UCRL-51929

\section{SOME OPTIMIZATIONS OF THE ANIMAL CODE}

\author{
W. T. Fletcher \\ October 9, 1975
}

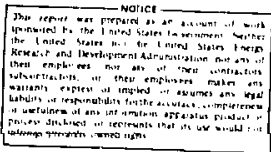




\title{
Some Optimizations of the Animal Code*
}

\author{
Abstract \\ Optimizing techniques were per- \\ - Simple Do-loops. \\ formed on a version of the ANIMAL code \\ (NALADIB) at the source-code \\ (FORTRAN) level. Sample optimizing \\ techniques and operations used in \\ MALADOP -- the optimized version of \\ the code -- are presented, along with \\ a critique of some standard CDC 7600 \\ optimizing techniques. The statistical \\ analysis of total CPU time required \\ for MALADUP and MALAD1B shows a run- \\ time saving of 174 msec (almost 3\%) \\ In the code MALADOP during one time \\ step. Optimizing strategies were \\ used for these FORTRAN programing \\ concepts: \\ - Two- and three-flmensional \\ arrays, \\ - Nested DO-loops in whlch an \\ inner loop has a small limit, \\ - Computation of constants in a \\ Dorloop, and \\ - Inefficient artihmetic opera- \\ tfons (multiplications and \\ divisions in FORTRW expres- \\ sions).
}

\section{Introduction}

The computer code ANIMAL - A New Implictt Magnetohydrodynamic Algorithm - Is a descendane of the original code developed to study theta plnches and laser produced plasmas. ${ }^{1}$ it has been used must recently to study

\footnotetext{
*Thts work was done as part or the Summer Computer Institute, 1975, held at Lawrence Livermore Laboratory. The author is currently at Princeton University.
}

toroidal theta pinches and sausage Instablities of siralght $z$ pinches.

This report presents the results of some optimizing tecliniques performed on a version of this code, called MALAD1B, at the source code level. The optimized version of the code, called MALADOp, achleved substantial run-time savings on the $C D C$ 7600. Sample optimizing techniques 
are presented. We also give a critique of some of the standard optimizing techniques described in Ref. 2, which we used to optimize the code. Certain cautions must be carefully observed when usting some of these techiques; our observations should be benefictal to a new user at LLL performing optimizations for the first time.

\section{Statistical Analysis of Run Time}

An analysis of CPU time for MALADIB and MIAADOP is given below:

Code: MALADOP

$$
\begin{aligned}
& \text { No. of sample pofnts taken } \\
& \text { in timing study: } 1429 \\
& \text { No. of time steps processed } \\
& \text { by MALADOP: } 1
\end{aligned}
$$$$
\text { Total CPU: } 5865 \mathrm{msec}
$$

Distribution of total cPU time, msec (main program and selected subroutines)

$\begin{array}{lr}\text { MAIN PROG } & 976.8 \\ \text { NXTZFLX } & 82.1 \\ \text { MAT2 } & 1296.9 \\ \text { L WAR } & 32.8 \\ \text { TRIANG } & 759.2 \\ \text { RFLX } & 274.9 \\ \text { ZFLX } & 57.5 \\ \text { TPANCO } & 86.2\end{array}$

\section{Code: MaLADIB}

No. of sample points taken in timing study: 1406 No. of time steps processed by MALAD1B: 1 Total CPU: $6039 \mathrm{msec}$
Distribution of total CPU tIme, msec (main program and selected subroutines)

$\begin{array}{lr}\text { MAIN PROG } & 979.3 \\ \text { NXTZFLX } & 77.3 \\ \text { MAT2 } & 1318.6 \\ \text { BOVAR } & 60.1 \\ \text { TRIANG } & 807.5 \\ \text { RFLX } & 240.5 \\ \text { ZFLX } & 51.4 \\ \text { TRANCO } & 77.3\end{array}$

Total time saved in MALADOP during one time step: 174 msec

MAIN PROG, MAT2, and TRIANG account for more than one-half of the total CPU time used by the codes and most of the optimlzation was done here. Efficiency gain was greatest in the eubroutine TRIANG, where the MALADOP version required $5 \%$ less time than the MALADLB version. Forty percent of the total CPU savings achieved occurred in these three rout ines. 


\section{Sample Optimizing Techniques}

This section gives examples of some optimizing techniques used in MA:Annl to improve execution efficiency. Fifforts to uptimize centered on these FonTRAN concepts:

- Simple DO-loops,

- Twu- and tiree-dimenstonal arrays,

- Cisted jun-loops in which an fune? loop has a smaj] limit,

- Computation of constants in a Dn-loop, and

- Inolficient arithnetic operations (multiplications and divisions) in FORThas expressions.

Fxample 1:

\section{MALADLIS's Method}

vo

35 VAR $(L+N D A D T)=R L(L)$

MAI.ADOP's Method

$\mathrm{NRZZ}=(\mathrm{NRZ} / 2) * 2$

DO $35 \mathrm{~L}=1$, NRZ2, 2

$\operatorname{VAR}(L+N D A D T)=R Z(L)$

$35 \operatorname{VAR}(L+1-$ NDADT $)=$

$1 \mathrm{RZ}(\mathrm{Lr}+\mathrm{l})$

IE (NRZ , GT. NRZ2)

2 VAR (NDADT + NRZ)

$3=\mathrm{R} 2(\mathrm{NR} 2)$
In $\because$ Hible's rigthod, the frequency of execution of the Do-lnop closing cole of the FORTRAN compller is halved.

Exampie 2:

MaLADIB's Method

UIMFASION $\mathrm{BC}(10,10,2), \mathrm{B}(10,10)$

Dn 650 L.L $=1, \mathrm{NW}$

un $650 \mathrm{sm}=1, \mathrm{NH}$

$050 B(L 1,29 I)=-B C(L L, 3 M, X x J)$

MALADOP's Yetinod

DIMFs 10N BC $(10,10,2), B(10,10)$

$\mathrm{NJMI}=100 *(\mathrm{xJJ}-1)$

DO $650 \mathrm{LL}=1, \mathrm{~N}^{\circ}$

LL.SE: = 12

$[\mathrm{SMJJ}=\mathrm{LL}+\mathrm{NJMI}$

$n, 650: 39:=3,50$

$B($ IIMS $)=-B C$ (LANJ)

1.LWH = LLNA + 10

$650 \quad 1.5 \mathrm{NJ}=$ L.SNJ +10

This example fllustrates the use of identities to zrarsform multipledimensional arrays into onedimensional arryys. MALADOP's method is twice as fast as the one used in MALAD1B, since expensive subscript computation has been simpliffed and memory fetches of each Index LL, MM, NNJ within the loop are replaced by a single fetch of LLMN and LNNJ. 


\section{Fyample 3:}

\section{MALADIB's Method}

$$
\begin{aligned}
& \text { DG } 41 \mathrm{~J}=1, \mathrm{NDR} \\
& \text { DO } 41 \mathrm{~K}=1, \mathrm{NDZ} \\
& \text { DO } 41 \mathrm{~L}=1, \mathrm{NV} \\
& J K L=J+N D A D T+N D R *((K-1)+ \\
& \text { 1. } \quad \operatorname{sD} 2 *(i-1)) \\
& L J K=L+N T I N E+N V *((J-1)+ \\
& 2 \operatorname{NDR} *(K-I)) \\
& 41 \operatorname{XLCM}(L J K)=\operatorname{VAR}(J K L)
\end{aligned}
$$

MaLADOP's Yethod

$$
\begin{aligned}
& \mathrm{NRNZ}=\mathrm{NDR} * \mathrm{SDZ} \\
& \mathrm{NVTR}=\mathrm{NV} * \mathrm{NIIR} \\
& \text { LJKI }=0 \\
& \text { Do } i 1 \mathrm{~J}=1, \mathrm{NDR} \\
& \mathrm{JKL}+2=0 \\
& \text { L.JK2 }=0 \\
& \text { DO } 42 \mathrm{~K}=1, \mathrm{NDZ} \\
& J K I=N D A D T+J+J k J 2 \\
& \mathrm{LJK}=\mathrm{NDADT}+\mathrm{J}+\mathrm{JKL2} \\
& L J K=\operatorname{sTLNE}+\mathrm{LJK} 2+\mathrm{LJK}]+1 \\
& \text { DO } 431 .+1, \mathrm{NY}^{\prime} \\
& \operatorname{XLCM}(L J K)=\operatorname{VAR}(J K L) \\
& L J K=1 \mathrm{JK}+1 \\
& 43 . \mathrm{IKL}=\mathrm{JKL}+\mathrm{NRN} . \mathrm{Z} \\
& \text { IJK2 }=\mathrm{LJK2}+\mathrm{NWDR} \\
& 42 \mathrm{JKL2}=\mathrm{JKL} 2+\mathrm{NDR} \\
& 41 L j k 1=L J K 1+N V
\end{aligned}
$$

This example 11justrates the use of programing techniques to Improve the efficiency of arithmetic operaflons appearing in a complicated FORTRAN expresston within a DO-loop.
The $2 *$ NV*Niz *NDR multiplications which occur in MALADIB's $\mathrm{FO}-$ loop have been replaced by two mutiplications outside SALADOP's nest of loops and additions within the loops. Since integer addition requires only 127600 clock periods and integer multiplication requires $15-20$ clock pertcds, the new method if is faster chan che old method in SaLADIH.

Fxample 4:

MiLADIB's Method

DIYKASIN: ABC $(10,10,3)$

D) $7601 .=1, \mathrm{xv}$

$L L=J 1 V N(1$.

$v(L)=v($ L.L.

Do $760 \mathrm{Y}=1$, $\mathrm{xV}$

$\mathrm{xy}=\mathrm{Jiv}(\mathrm{N})$

DO $760 \mathrm{~N}=1,3$

$760 \quad A B C(L, N, N)=A B C$ (II., SN, N)

MALADOP's Method

DO $760 \mathrm{l} .=1, \mathrm{NV}$

LL = JIVV (L)

$V(L)=v(L L)$

I.MH $=L$

Do $760 \mathrm{~N}=1$, NV

$\mathrm{M}=\mathrm{J} \perp \mathrm{VV}(\mathrm{M})$

LLMN $=$ I.L + $10 *($ SM - 1)

$A B C$ (INN) = ABC (LLNN)

$A B C(L M N+100)=A B C(L L N+100)$

$A B C(L M N+200)=A B C(L L N N+200)$

760 LMN $=$ LMN +10 
Since even a simple on-loop

requires uxpensive stores and fetches, "unwindinf' bn-locps matually gafns execution efficiency. The above example tllustrates this technique.

Ixample 5:

MillaDIB's Method

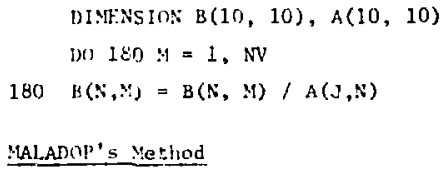

$\mathrm{NN10}=1 ! * \mathrm{~N}-10$

AWS $=1 . / \mathrm{A}($ NH1O $)$

$\mathrm{BM}=\mathrm{x}$

In $180 \mathrm{y}=1$, NV

$B(\mathrm{~N} 2)=B(\mathrm{M} 2)$ *ANNS

$180 \quad x 42=3942+10$

livtdus are quite slow (requirtng 307600 clock pertods) and when performed wititin a bo-loop, they can appreciably affect the time renuired to evaluate arithmetic expressions. This example 111 ustrates a method which transforms floating-point dfufdes Into floating-point multiplizations which reouire 15 CDC 7600 clock periods.

\section{Example 6:}

FOGDT $=$ YDDT * RO * RTG $/ D T$

$V(6)+V(6)+E I * T 2 I+E I *$ ROGDT

MaLADOP's Method

ROGDT = SNDT * RO* (RTG/DT)

$v(6)=V(6)+V I *(T 21+$ roGDT $)$

The expression ROGDT = XDDT * RO

* (RTC/DT) is iaster than ROCD $L^{\prime}=$ XDDT * RO * RTG/DT, because in the former case, the 'ivide is being done while KDDT and RO are fetched and multipiled. In the latter case, the divide is done last and the result is stored after a full 20-clock-cycle watt for the divida to complete.

\section{Cautions}

When a programner is asked to optimize a code wlich he did not write orfiginally and which he doesn't know much about, he must be extremely careful not to alter the logic of the original code. In this section, we present some croublesome statements where optimization of the MALADlB code produced logical errors. These exrmples serve as warnings to other programmers to avoid the suthor's errors and, equally important, serve as guides -- should an error occur -to flaces to look for errors during the debugging state. 


\section{Example 7:}

old Method

$$
\begin{aligned}
& \text { DO } 208 L=1 \text {, NBLh } \\
& 208 \text { K2BC }(L)=1 \\
& \text { New Method } \\
& \text { NB2 }=(N B C H / 2) \star 2 \\
& \text { DO } 208 L=1, N B 2,2 \\
& \text { K2BC }(L)=1 \\
& \text { K2BC }(L+1)=1 \\
& \text { IF (NBCH .GT. NB2) K2BC (NBCH) }=1
\end{aligned}
$$

Rersirk:

When $\mathrm{NBCH}=1$, the new method is invalid, since tt sets the value of the element $\mathrm{K} 2 \mathrm{BC}(2)$ equal to 1 . In the old method, this element does not recelve the value of $]$ in the DO-1oop.

\section{Example 8:}

old Mechod

$$
\begin{aligned}
& \text { DTMENSION } A(10,10), B(10,10), \\
& 1 \quad C(10,10) \\
& \text { UO } 160 \mathrm{LL}=1, \mathrm{NV} \\
& \mathrm{B}(\mathrm{N}, \mathrm{LL})=\mathrm{B}(\mathrm{N}, \mathrm{LL})-\mathrm{A}(\mathrm{NMI}) \star \\
& 2 \quad \mathrm{~B}(\mathrm{M}, \mathrm{LL}) \\
& \text { I } \overrightarrow{\mathrm{r}}(\mathrm{IF} 1 . \mathrm{NE} .2) \mathrm{GO} \text { TO } 160 \\
& \text { DO } 160 \mathrm{LL}=1, \mathrm{NV} \\
& \mathrm{C}(\mathrm{N}, \mathrm{LL})=\mathrm{C}(\mathrm{N}, \mathrm{LL})-\mathrm{A}(\mathrm{NMI}) * \\
& 3 \quad \mathrm{C}(\mathrm{M}, \mathrm{LL}) \\
& 160 \mathrm{~A}(\mathrm{NM} 1)=0,0
\end{aligned}
$$

\section{New Sethod}

$$
\begin{aligned}
& \text { DIMENSION } A(10,10), B(10,10) \text {. } \\
& 1 \quad c(10,10 \\
& \mathrm{NH}=\mathrm{X} \\
& M=X \\
& \text { LNM }=\mathbf{N} \\
& \text { L:D! }=: 4 \\
& \text { D) } 160 \text { L.L }=1, \mathrm{XV} \\
& B(\text { LNM })=B(\text { LNM })-A(\text { N1 }) * \\
& 2 \quad B(L M N) \\
& \text { IF (IFI NE. 2) GO TO } 160 \\
& \text { DO } 161 \text { LL + I, NV } \\
& C(N O)=c(N)-A(N D) * \\
& 3 \quad \mathrm{C}(\mathrm{M} M) \\
& \mathrm{NM}=\mathrm{NM}+10 \\
& A(N-1)=0.0 \\
& L M N=L A N+10
\end{aligned}
$$$$
161 S M+S M+10
$$$$
160 \mathrm{LMH}=\mathrm{LAM}+10
$$

\section{Remark:}

The new method in the above example contains a logical error. When IF $1 \neq 2$, control is transferred to statement number 160 containing the expresston $L M M=L M M+10$, but control should have been transferred to the statement contatning the expresston $A(N N 1)=0.0$. This error can be easily corrected.

\section{General Remark:}

References made to a multipledimension array using integer variable tndices $[\mathrm{e} . \mathrm{g} ., A(I, J)$ or $A(I, J, K)]$ 
:equire constderable run-t 1me computa$t$ ion. it hill increase efficlency to transform these arrays to onedimensional arrays, is 11lustrated in previous examples.

When the arrays are referenced with integer constant indices, however. no such run-time computation occurs
Sat least on LLL's P(T compiler), so no advantage is galned by such a transf ormation.

(In this connection, it is interesting to note that LLL's PLTT compliar does not accept array findices of the forp $I * K$. It does, however, accept indices of the form $1: k$.)

\section{References}

1. 1. lindemuth and J. Killeen, J. Comp. Phys. 13, 181 (1973).

2. F. KeGire, K. J. Melendez, and L. Rudsinsk1, "CDC 7600 ForTRAs Optimizing Techniques, Los Alamos Sclentific Laboratory, Rept. LA-5219-YS, LC-32 (June, 1973). 